\title{
PROFESSORES DE VIOLÃO PARA CRIANÇAS: UM ESTUDO \\ SOBRE ESTRATÉGIAS E ABORDAGENS ADOTADAS EM \\ CURSOS DE LICENCIATURA EM MÚSICA
}

\section{MAESTROS DE GUITARRA PARA NIÑOS: UN ESTUDIO SOBRE \\ LAS ESTRATEGIAS Y LOS ENFOQUES UTILIZADOS EN \\ CURSOS DE PROFESORADO EN MÚSICA}

DOI: http://dx.doi.org/10.5965/1984317813032017008

Regina Finck Schambeck, Roveli Bichels, Willian Mota Caitano dos Reis - Universidade do Estado de Santa Catarina

\begin{abstract}
RESUMO
A presente pesquisa apresenta foco no ensino de violão de crianças na faixa etária de cinco a doze anos. Busca-se verificar o que pensam professores que atuam em cursos de graduação sobre o ensino de violão para crianças, investigando-se as estratégias e abordagens utilizadas para a preparação dos professores de instrumentos que atuarão com o público infantil. Para isto, utilizou-se como metodologia de pesquisa a abordagem qualitativa, através de revisão bibliográfica e aplicação de questionário autoadministrado enviado a professores que atuam ou atuaram em nove cursos de licenciatura em música em diferentes estados brasileiros. Apurou-se que a maioria dos professores participantes utiliza propostas de trabalho com base no ensino coletivo do instrumento; ressalta a importância da afetividade na relação professor-aluno; reconhece como fator determinante para a aprendizagem do instrumento violão o conhecimento sobre o desenvolvimento cognitivo da criança; e recomenda a utilização de atividades lúdicas para melhorar a aprendizagem do instrumento.
\end{abstract}

Palavras-chave: Educação musical. Violão. Criança. Ensino.

\section{RESUMEN}

Esta investigación presenta un enfoque en la enseñanza de guitarra a niños de cinco a doce años. Se busca comprobar qué piensan los docentes que trabajan en cursos de graduación sobre la enseñanza de la guitarra para niños, investigando las estrategias y enfoques que se utilizan para la preparación de los profesores del instrumento que actuará con el público infantil. Para ello, se utilizó como método de investigación un enfoque cualitativo, a través de revisión bibliográfica y aplicación de cuestionario auto administrado, enviado a los docentes que trabajan o han trabajado en nueve cursos de graduación en música en diferentes Estados de Brasil. Fué posíble darse cuenta de que la mayoría de los profesores participantes mencionó el uso de propuestas de trabajo basada en el aprendizaje colectivo del instrumento, destacaron la importancia de la afectividad en la relación maestro-alumno, reconocieron como un factor determinante para el aprendizaje del instrumento guitarra el conocimiento sobre el desarrollo cognitivo del niño y recomiendan el uso de actividades lúdicas para mejorar el aprendizaje del instrumento.

Palabras-clave: Educación musical. Guitarra. Niños. Enseñanza. 


\section{INTRODUÇÃO}

Esta investigação surgiu de uma reflexão sobre os processos de preparação profissional para professores que atuarão no ensino de violão para crianças. $\mathrm{O}$ questionamento inicial pautou-se em discussões sobre se a formação instrumental na licenciatura deveria formar o professor de instrumento para diferentes públicos ou se essa preparação caberia aos cursos específicos de licenciatura em instrumento, tal como previsto nos documentos oficiais que definem os preceitos norteadores dos projetos pedagógicos dos cursos de Licenciatura em Música, como a Resolução do Conselho Nacional de Educação, CP n. 1, de 18 de fevereiro de 2002, fundamentada nos pareceres CNE/CP 9/2001 e 27/2001, que institui as Diretrizes Curriculares Nacionais para a Formação de Professores da Educação Básica, em nível superior, curso de licenciatura, de graduação plena, tratando dos princípios, fundamentos e procedimentos para a organização institucional e curricular dos cursos de licenciatura, isto é, de graduação plena. No que se refere aos cursos de música (conforme a Resolução n. 2/2004, que aprova as Diretrizes Curriculares Nacionais do Curso de Graduação em Música), estão dispostos os seguintes tópicos de estudos ou de conteúdos relacionados entre si: conteúdos básicos, conteúdos específicos e conteúdos teórico-práticos.

Acredita-se que seja diferente o perfil do profissional egresso dos cursos de licenciatura em música e licenciatura em instrumento, uma vez que também será diferente pensar em professores de música que tocam um instrumento enquanto formação musical/do músico e aqueles que tocam com a intenção de ensinar esse instrumento, independentemente da faixa etária à qual ele se destina.

Esta é uma discussão recorrente da área de formação de professores de música, sendo que alguns cursos criaram as licenciaturas em instrumento para dar conta da formação desse profissional - o professor de instrumento. Enquanto que, na maior parte das licenciaturas em Música, formam-se professores para a educação básica, não para a aula de instrumento. Assim, se, por um lado, tem-se a legislação e os projetos pedagógicos dos cursos de licenciatura, que ajudam a compreender como se dá a 
formação desse profissional, por outro lado, há também os espaços onde esse profissional atuará.

Neste texto, discute-se, então, a realidade encontrada nos ambientes de escola livre de música, onde as aulas do instrumento violão, normalmente, acontecem individualmente, uma vez na semana e têm, em média, uma hora de duração. O público dessas aulas, na sua grande maioria, é formado por jovens, mas também um grande número de adultos busca nas aulas de instrumento a realização de um desejo muitas vezes postergado. Além dos adultos que procuram aulas de instrumento, observa-se que crianças cuja a faixa etária varia entre cinco e doze anos de idade também têm buscado por essas aulas.

Justifica-se, portanto, o recorte da temática sobre o ensino de violão para a faixa etária e com foco na criança pelo fato de ser este o público com o qual se observam menor produção bibliográfica e as maiores dificuldades em se conduzir o processo de ensino e aprendizagem do instrumento em questão.

Sendo assim, na busca por uma ampliação de conhecimentos sobre a temática de ensino do instrumento violão para crianças, reflete-se, com este artigo, sobre as abordagens metodológicas que podem ser utilizadas para um melhor aproveitamento das atividades, de modo que a aula de violão possa também colaborar para os processos de musicalização desse público, em especial, dadas as caraterísticas de aprendizagem e desenvolvimento físico-motor da faixa etária.

Ao delimitar-se a temática da pesquisa com foco no ensino do instrumento violão para crianças de cinco a doze anos de idade, algumas questões surgiram: o que pensam professores que atuam em cursos de graduação sobre o ensino de violão para crianças? Que estratégias esses professores utilizam, visando a preparação do profissional que atuará com esse público? Que materiais pedagógicos utilizam em suas aulas? A partir destes questionamentos, investigou-se como professores que atuam em cursos de graduação discutem o ensino do instrumento violão para a infância, identificando-se estratégias e abordagens utilizadas nas práticas pedagógicas de preparação do futuro profissional que atuará nesse campo. 
De acordo com o levantamento da literatura feito por Reis (2016), são poucos os métodos que discutem perspectivas de ensino de violão para crianças na faixa etária de cinco a doze anos. A partir das dificuldades de conexão entre o perfil de aprendizagem do grupo de alunos e a falta de trabalhos científicos sobre as metodologias específicas e estratégias de ensino, neste artigo, busca-se fazer uma aproximação entre a organologia do instrumento violão e as características de aprendizagem desse público.

Este trabalho tem como base a abordagem qualitativa com ênfase na aplicação de questionários autoadministrados para professores de violão que atuam ou atuaram em nove cursos de Licenciatura em Música de diferentes estados brasileiros. Fazem parte das análises de dados as respostas de cinco professores que atenderam aos critérios estabelecidos, quais sejam, ser docente universitário com atuação como professor de violão junto ao público infantil e discutir questões relacionadas ao ensino de violão para tal público em suas aulas na graduação.

\section{METODOLOGIA}

O presente trabalho utiliza a abordagem qualitativa apresentando um enfoque exploratório e descritivo. A pesquisa qualitativa diz respeito ao entendimento de uma realidade ou fenômeno pela perspectiva daqueles que dele participam e na tentativa de compreender conceitos básicos e introdutórios da temática abordada em um processo de construção de conhecimento.

Geralmente, um desenho de pesquisa qualitativa descreve o "[...] propósito do estudo e os tipos de perguntas que estão sendo tratados, as técnicas a serem usadas para coletar os dados, as abordagens à seleção de amostras e como os dados serão analisados" (GRAY, 2012, p. 108). Neste sentido, investigou-se como professores que atuam em cursos de graduação discutem o ensino do instrumento violão para a infância, identificando-se estratégias e abordagens utilizadas nas práticas pedagógicas.

A unidade de análise passou, então, pelos materiais, métodos, abordagens e estratégias mencionadas pelos professores de ensino superior que atuam com o ensino 
do instrumento violão. Buscou-se, com a abordagem qualitativa, uma aproximação com o objeto de pesquisa, ou seja, o ensino de violão para crianças, levando o pesquisador a uma maior aproximação e detalhamento das práticas direcionadas para a faixa etária de cinco a doze anos.

Godoy (1995, p. 24) sugere que a revisão bibliográfica deva seguir uma ordem de pesquisa, efetuando-se primeiramente uma pré-análise, em seguida, fazendo-se a exploração do material e, por fim, tratando-se dos resultados.

Neste trabalho, na fase da pré-análise, exploraram-se métodos e textos que discutem o ensino de violão para crianças, escolhendo-se os materiais disponíveis em língua brasileira voltados ao ensino coletivo e individual de violão. Feita esta organização do material encontrado e mediante leituras e fichamentos, procedeu-se à organização desses dados.

Através da revisão bibliográfica, foram encontrados e analisados materiais pedagógicos direcionados ao ensino de violão para crianças. Esta constituiu-se como a primeira etapa do trabalho, em que se investigaram as propostas pedagógicas, os conteúdos musicais, elementos técnicos e abordagens didáticas para o ensino individual e coletivo (REIS; SCHAMBECK, 2017, REIS, 2016) ${ }^{1}$.

$\mathrm{Na}$ segunda etapa da pesquisa, foi desenvolvido o roteiro do questionário autoadministrado. Segundo Moysés e Moori (2007, p. 2), o questionário autoadministrado tem por objetivo desenvolver “[...] um conjunto de perguntas ordenadas de acordo com um critério predeterminado, [...] respondido sem a presença do entrevistador". Esse tipo de questionário procura obter perguntas focalizando respostas mais específicas e diretas. Sua aplicação ocorre eletronicamente através da coleta de dados on-line. (HAIR, 2004, p. 160 apud MOYSÈS; MOORI, 2007, p. 3).

O roteiro continha duas seções de perguntas. A primeira visava apurar se o docente universitário já tinha atuado como professor de violão junto ao público infantil.

1Reis; Schambeck (2017) pode ser acessado em https://grupodepesquisamuse.files.wordpress.com/2017/07/anais-do-vii-encontro-do-muse.pdf Reis (2016) pode ser acessado em http://pergamumweb.udesc.br/biblioteca/index.php?resolution2=1024 1 
Nesta sessão, as perguntas estavam relacionadas ao ensino de violão para crianças, faixa etária das turmas, conteúdos abordados, métodos utilizados, se havia desenvolvimento de material didático, como eram preparadas as aulas, e se eram coletivas ou individuais. Ainda, elaborou-se uma questão aberta com a possibilidade de o colaborador indicar os materiais utilizados para apoio pedagógico.

$\mathrm{Na}$ segunda sessão, as questões estavam relacionadas ao ensino de violão para tal público nas aulas da graduação, abrangendo perguntas direcionadas à preparação do futuro professor que atuará com o público infantil. Foram questões sobre os conteúdos abordados e as metodologias e/ou métodos do ensino de violão que são adotados. Da mesma forma, foi proposta uma questão aberta para que o colaborador desse a sua opinião sobre a preparação de alunos de violão (Licenciatura em Música) para atuar com o público infantil.

Foram enviados e-mails de contato para nove instituições de ensino superior que abrigam cursos de Licenciatura em Música. Nestas mensagens, havia um texto com as devidas explicações do objeto da pesquisa e a solicitação do envio dos nomes e dos endereços eletrônicos dos professores de violão daquelas unidades. Obtendo-se o retorno com as indicações, os professores foram acionados e convidados a participar da pesquisa. Dos onze professores convidados a participar, sete responderam. Destes, apenas cinco informaram ter experiência com o ensino de violão direcionado para crianças: Sarah, Fabio, Matheus, Marcelo e Dante. Portanto, apenas esses farão parte das análises dos dados da pesquisa.

\section{ANÁLISE DOS DADOS}

Nesta parte do texto, apresentam-se os dados sobre a preparação do professor de violão de cursos superior de música para atuar com o público infantil.

Dentre os entrevistados, apurou-se que a média de faixa etária trabalhada ocorre a partir dos sete anos de idade e nenhum dos professores mencionou ter atuado com crianças entre cinco e seis anos. 
Nas aulas de violão direcionadas para o público infantil acima de sete anos, a professora Sarah se concentra apenas na atuação do ensino coletivo. Já o professor Fabio indica ministrar aulas individuais. Os professores Matheus e Marcelo mencionaram adotar aulas coletivas e também individuais. E o professor Dante não mencionou a forma como atua.

\subsection{EXPERIÊNCIA PESSOAL COM O ENSINO DE INSTRUMENTO PARA CRIANÇAS}

De maneira geral, os professores participantes da pesquisa entendem que o ensino de violão para crianças deve ser muito bem planejado. Entre os principais itens para se ter maiores cuidados foram mencionados a fragilidade física do pequeno instrumentista, as indicações da postura adequada para tocar o instrumento, as pressões familiares sofridas para a aprendizagem do violão e a afinidade do professor em trabalhar com essa faixa etária, principalmente para manter o foco pedagógico, uma vez que, segundo os professores, nem todas as crianças apresentam habilidade nata para a prática instrumental. Deste modo, sob o ponto de vista dos participantes da pesquisa, as aulas devem ser planejadas para manter o interesse das crianças e focar na musicalização, nos processos de aprendizagem do violão.

O ensino do instrumento para crianças deve ser extremamente cuidadoso, individualizado, sendo que cada aluno tem suas facilidades e dificuldades, cada um tem uma potencialidade, um limite, um tempo próprio de assimilação e minha opinião é que essa particularidade deve ser respeitada. (Questionário - professora Sarah, 2016).

O professor Marcelo, ao relatar sobre o ensino de música para as crianças, diz que acredita que a aprendizagem instrumental ajuda no desenvolvimento cognitivo.

É de fundamental importância para o desenvolvimento de várias funções das crianças, desde melhorar a coordenação motora, o raciocínio lógico, o respeito pelo colega, favorecer a sociabilidade durante o convívio com os colegas de aula, curso ou turma. O aprendizado do instrumento, e consequentemente a alfabetização musical, durante esta faixa etária, é fundamental para um bom desenvolvimento no instrumento, quanto mais cedo se der o contato formal com a música melhores serão os benefícios futuros, tanto na música quanto das demais disciplinas do ensino regular. (Questionário - professor Marcelo, 2016). 
O trabalho com o público infantil leva os professores Dante, Matheus, Fabio e Sarah a concluir que a criança deve ter um cuidado especial no que tange à musculatura, ainda pouco desenvolvida na infância. Dante relata que, na prática do instrumento, se essa questão não tiver uma atenção especial ou for mal ministrada, o aprendizado “[...] pode levar a má postura corporal, lesões musculares e até ao abandono da prática musical". Sarah complementa explicando que "[...] desde o início, deve-se evitar más posturas e vícios para que o ‘erro' não fique gravado na memória” (Questionário, 2016).

Os professores Fabio e Sarah reforçam que o educador deve ter o conhecimento não somente dos aspectos fisiológicos, mas também dos aspectos psicológicos da criança. Compreender como ocorre a "[...] consolidação das memórias, conhecer estratégias de ensino e sempre buscar motivar os alunos para que prossigam com o estudo do violão" (Questionário - professora Sarah, 2016). No material didático Sonhando em Cordas, Comini, Filho e Victor (2016) trazem à tona uma preocupação com o desenvolvimento cognitivo da criança, propondo, para tanto, atividades musicais de acordo com suas faixas etárias. Desta maneira, ao oferecer atividades apropriadas para a fase cognitiva e física, os estudantes serão levados a "[...] resultados mais satisfatórios na compreensão pelo conteúdo e no desenvolvimento musical". (COMINI; BARRETO FILHO; VICTOR, 2016, p. 4).

Outro ponto relevante para as atividades de ensino de violão para crianças de cinco a doze anos foi mencionado pelo professor Fabio: a afetividade. Ele revela sua preocupação em mantê-la viva entre professor e aluno e coloca este aspecto como sendo fundamental para o aprendizado da criança.

Creio ser necessário que o professor tenha uma identificação afetiva muito forte com crianças, com o mundo da criança e com os processos cognitivos próprios da criança. Pois, se vamos pensar em didática do violão para crianças, não devemos pensar apenas nos indivíduos excepcionais (em interesse e dedicação), mas, sim, nas crianças de forma geral. (Questionário - professor Fabio, 2016).

Nunes e Faria (2011, p. 8) reforçam o entendimento do professor Fabio sobre a importância da relação de afetividade ente professor e aluno ao explicarem que "[...] o tipo de relação que estabelecemos com o aluno pode gerar confiança e um aumento de 
atenção que são condições indispensáveis para a aprendizagem”. Os autores reforçam que por meio do afeto o aluno obterá maior confiança e atenção sobre o que o professor lhe estiver ensinando.

Silva (2013) descreve que o vínculo entre professor e aluno contribui significativamente para o desenvolvimento cognitivo da criança, visto que, através da afetividade, o aluno passa a sentir-se valorizado, o que contribui para a motivação do estudante no desejo de apreender. Ressalta ainda a autora que "[...] o desenvolvimento intelectual abrange dois lados: um afetivo e um cognitivo, ou seja, é impossível desvincular a afetividade da cognição, ou o contrário" (SILVA, 2013).

Assim, acredita-se que é pelo estabelecimento do vínculo afetivo que o aluno é levado a interessar-se e ter maior atenção pelo conteúdo ensinado. Neste sentido, se o professor não tiver um envolvimento emocional satisfatório, o trabalho pedagógico tende a torna-se mais difícil, maçante e, até mesmo, infrutífero. Para Silva (2013), é através do afeto que o emocional do estudante é fortalecido e, consequentemente, seu aprendizado melhor assimilado.

As reações emocionais exercem uma influência essencial e absoluta em todas as formas de nosso comportamento e em todos os momentos do processo educativo. Se quisermos que os alunos recordem melhor ou exercitem mais seu pensamento, devemos fazer com que essas atividades sejam emocionalmente estimuladas. (VYGOTSKI apud SILVA, 2013).

Deste modo, pode-se concluir que a prática pedagógica sem envolvimento afetivo repercute de modo negativo no desenvolvimento cognitivo. Sendo assim, é importante que o professor de violão, conforme indicou o professor Fabio, mantenha a afetividade como um elemento significativo nas atividades de ensino do instrumento violão para crianças.

Ainda sobre a aprendizagem musical para crianças, os professores afirmam que,

Nesta etapa de ensino [referindo-se ao trabalho com a infância], conhecimentos sobre psicomotricidade infantil, educação especial e inclusiva podem ser importantes; estudos de Piaget e Vigotski que falam sobre aprendizagem também são úteis. (Questionário professor Dante, 2016). 


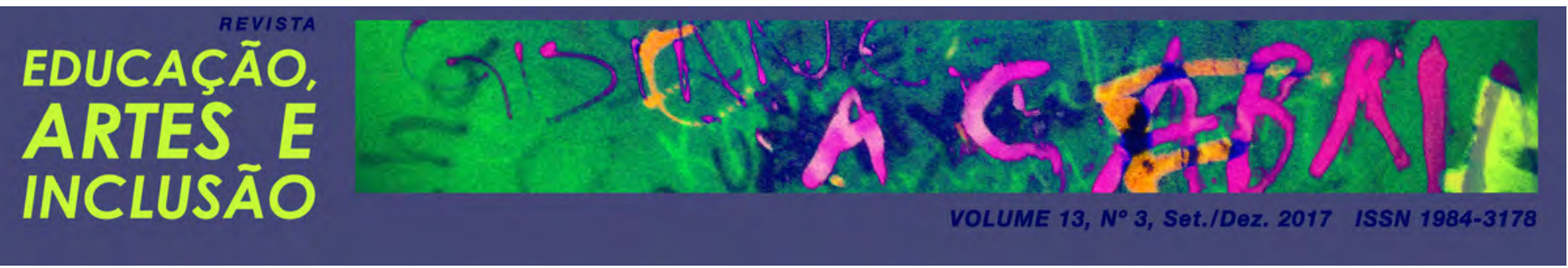

O professor de violão, para atuar com o público infantil, deverá estudar sobre a psicologia da aprendizagem e conhecer as faixas etárias. Ser responsável, profissional e ético com seus alunos, transmitir o conhecimento de forma clara, não deixar passar detalhes, que futuramente poderão trazer problemas técnicos e musicais. (Questionário - professora Sarah, 2016).

Esta faixa etária é particularmente delicada, pois a criança ainda está com seu corpo em desenvolvimento e formação. Deve-se tomar muito cuidado com algumas coisas, como: a escolha do instrumento adequado, ele deve ser compatível com o tamanho da criança; e o processo de iniciação, evitando movimentos, acordes, exercícios que exijam muito das mãos, pois o risco de lesão é muito grande. Uma iniciação musical e instrumental bem feita ficará marcada para sempre na formação da criança como um momento de aprendizado prazeroso, de criação, de alegria, de boas lembranças, contribuindo imensamente para a sua continuação no universo musical. Uma iniciação sem planejamento, por pessoas não capacitadas, além de ser perigosa para a saúde da criança, será lembrada como algo ruim, sem valor, gerando muitas vezes a sensação de incapacidade de aprendizado do instrumento, o que nem sempre é verdade, pois pode ser que a metodologia utilizada não tenha sido a mais adequada. (Questionário professor Marcelo, 2016).

Segundo os professores colaboradores desta pesquisa, os conteúdos abordados no ensino de violão para as crianças focam-se em harmonia, história da música, execução de solos e acompanhamentos, acordes, levadas rítmicas, questões da técnica violonística, postura, posição das mãos e leitura musical, conforme se verifica nos comentários acerca dos conteúdos ministrados:

[...] leitura musical, harmonia, história, execução de solos e acompanhamentos, através dos planos do curso e de aula alinhados à filosofia e grade curricular da instituição/escola; [...] (Questionário professor Dante, 2016).

[...] acordes e levadas rítmicas para o repertório de música popular brasileira e exercícios com leitura musical em partitura, trabalhando questões da técnica violonística como posturas e posição das mãos; [...] (Questionário - professora Sarah, 2016).

[...] conteúdos na proposta da escola e no interesse do aluno, como: postura, conhecimento do instrumento, localização das notas, repertório, cifragem, leitura de partitura etc.; [...] (Questionário professor Matheus, 2016).

Ministrei aulas [...] com conteúdos extraídos dos livros do Henrique Pinto, Othon Rocha, Isaias Sávio, além de canções folclóricas 
transcritas para violão por mim e demais professores da escola. (Questionário - professor Marcelo, 2016).

O Professor Fabio não mencionou quais conteúdos ele trabalha com os alunos de sete e nove anos, faixa etária com a qual afirma ter trabalhado, relatando que, “[...] apesar de conhecer os métodos disponíveis no mercado, pouco os utilizei" (Questionário - professor Fabio, 2016).

Com relação aos conteúdos trabalhados, pode-se afirmar que utilizar atividades relacionadas ao contexto da criança é fundamental para estabelecer um vínculo com o estudante. A partir disso, o aluno será impulsionado a ter motivação a aprender, acelerando ou retardando seu desenvolvimento e otimizando sua relação com o aprendizado. Neste sentido, o professor Matheus afirma que a proposta pedagógica adotada para o ensino de violão aproxima-se aos princípios de Paulo Freire, referencial adotado pela escola onde ele atua. O professor procura sempre "[...] respeitar o lugar de onde a criança vem, mantendo um profundo respeito por seus conhecimentos prévios, interesses e limitações" (Questionário - professor Matheus, 2016). Ele comenta ainda que a preparação das aulas dá-se em parceria com os alunos, justamente para estabelecer com eles esse elo de afetividade.

Os professores adotam materiais didáticos que normalmente são fornecidos pela própria escola ou, então, utilizam seus próprios materiais, escrevem arranjos e realizam atividades sugeridas com métodos direcionados para o público infantil, disponíveis no mercado.

Produzo meus próprios materiais didáticos, com planos de curso e de aula. Utilizo os métodos de "Ciranda das Seis Cordas", de H. Pinto, "A Jugar y cantar com la guitarra", de Gainza e Kantor, e "Violão Clássico", de Irineu Kruger. (Questionário - professor Dante, 2016).

O material didático que utilizo é a apostila da escola e material pessoal, contendo canções cifradas e partituras. (Questionário professora Sarah, 2016).

Utilizo alguns métodos apenas como consulta e sugestões de repertório e/ou exercícios. Como metodologia básica, parto do repertório conhecido pelo aluno, procurando alternativas de dedilhados e posições que a criança tenha mais facilidade, o que muda de criança para criança. (Questionário - professor Matheus, 2016). 
Prefiro fazer arranjos de canções infantis e outras conhecidas dos alunos. (Questionário - professor Fabio, 2016).

Extraí os conteúdos dos livros do Henrique Pinto, Othon Rocha, Isaias Sávio, além de canções folclóricas transcritas para violão por mim e demais professores da escola. Desenvolvi materiais didáticos para o ensino do violão, transcrições, arranjos e composições publicados posteriormente [...]. Duas destas publicações são apropriadas para iniciação ao violão, sendo elas "Caderno Pedagógico - Uma sugestão para iniciação ao violão" e "Minhas Primeiras Cordas", com composições para iniciantes. (Questionário - professor Marcelo, 2016).

O repertório tem uma importância fundamental para o progresso do aluno, para sua motivação e o estabelecimento de caminhos que o estudante percorrerá. Através dos critérios estabelecidos em suas peças, essa escolha pode servir como uma resolução de problemas ao estudante. (FIREMAN, 2007, p. 97). Deste modo, é importante que o repertório estabelecido contenha atividades que estimulem as crianças, estando de acordo com sua faixa etária e seu nível técnico e sendo compatível à sua realização.

De acordo com os relatos dos professores, percebe-se que suas dificuldades em atuar com o público infantil estão relacionadas ao desenvolvimento da musculatura da criança; à manutenção do interesse dos alunos; à autonomia da criança em estudar fora do horário de aula; à sobrecarga de atividades extras que a criança pratica e que influenciam no aprendizado musical, entre outros.

Em muitos casos, revela-se que o interesse no estudo da música vem da família e não propriamente da criança, podendo este ser um grande dificultador para o aprendizado. Sobre isso, o professor Matheus, ao relatar suas dificuldades ao atuar com esse público infantil, coloca que, “[...] geralmente, o interesse para o estudo da música é dos pais e não propriamente das crianças, o que inviabiliza qualquer trabalho pedagógico" (Questionário - professor Matheus, 2013).

Dante ressalta como dificuldade a questão da autonomia para o ato de estudar e sugere que o acompanhamento de um familiar ou responsável, em alguns casos, pode tornar-se positivo até que esteja instalado o hábito do estudo. 
Para o professor Fabio, a dificuldade está em ter empatia com as crianças. Ele explica que, muitas vezes, “[...] as crianças vêm para a aula de violão/guitarra para se sentirem artistas famosos de mídia e não querem necessariamente aprender a tocar o instrumento" (Questionário - professor, Fábio, 2016).

O professor Marcelo menciona que a dificuldade em trabalhar com o público infantil reside na sobrecarga de atividades extras das crianças.

A aula de instrumento não é a única atividade extra que a criança faz, dividindo seu tempo com aulas de reforço escolar, natação, balé, artes marciais, línguas estrangeiras, entre outras. Essa sobrecarrega de atividades influencia diretamente no desenvolvimento do aprendizado instrumental, pois, nem sempre, as crianças vão estudar um instrumento musical por vontade própria, o que pode ser também um dificultador do aprendizado instrumental. (Questionário - professor Marcelo, 2016).

A partir das dificuldades apresentadas, como educador, deve-se buscar por soluções para que a criança se motive a aprender o instrumento.

[...] dificuldade de aquisição e manutenção de um bom instrumento; aquisição de materiais didáticos, obrigando à maioria dos alunos a fazer cópias de métodos, apostilas, álbuns, coleções e partituras diversas; dificuldade de afinação do instrumento. (Questionário professor Marcelo, 2016).

De acordo com o levantamento realizado juntamente com os professores participantes desta pesquisa, pôde-se apurar a menção aos seguintes métodos:

Quadro1 - Indicação de métodos adotados

\begin{tabular}{|l|l|l|}
\hline Professor & \multicolumn{1}{|c|}{ Método Mencionado } & \multicolumn{1}{|c|}{ Autor } \\
\hline \multirow{4}{*}{ Dante } & O amigo violão & Ricardo Novais \\
\cline { 2 - 3 } & O equilibrista das seis cordas & Silvana Mariani \\
\cline { 2 - 3 } & Ciranda das seis cordas & Henrique Pinto \\
\cline { 2 - 3 } & A jugar y cantar com la guitarra & Gainza; Kantor \\
\cline { 2 - 3 } & Violão clássico & Irineu Kruger \\
\cline { 2 - 3 } & Métodos de violão (não há menção clara ao & Hal Leonard \\
\hline
\end{tabular}




\begin{tabular}{|c|c|c|}
\hline & título dos métodos) & \\
\hline Sarah & $\begin{array}{l}\text { Caderno pedagógico: uma sugestão para } \\
\text { iniciação ao violão }\end{array}$ & $\begin{array}{l}\text { Jodacil Damaceno e André Campos } \\
\text { (EDUFU, 2002) }\end{array}$ \\
\hline \multirow{4}{*}{ Matheus } & O equilibrista das seis cordas & Silvana Mariani \\
\hline & Método de violão para crianças & UFPR (2002) \\
\hline & Ciranda das seis cordas - iniciação infantil & Henrique Pinto \\
\hline & Métodos de violão & $\begin{array}{l}\text { Othon Gomes Filho, Mascarenhas, } \\
\text { Henrique Pinto Suzuki }\end{array}$ \\
\hline \multirow[t]{2}{*}{ Fábio } & O equilibrista das seis cordas & Silvana Mariani \\
\hline & Ciranda das seis cordas & Henrique Pinto \\
\hline \multirow[t]{7}{*}{ Marcelo } & O equilibrista das seis cordas & Silvana Mariani \\
\hline & Na ponta dos dedos, para cordas dedilhadas & Marcelo Brazil \\
\hline & First book for the guitar & Frederick Noad \\
\hline & Ciranda das seis cordas - iniciação infantil & Henrique Pinto \\
\hline & Métodos de violão & Othon Rocha, Isaias Sávio \\
\hline & Minhas primeiras cordas & André Campos Machado \\
\hline & $\begin{array}{l}\text { Caderno pedagógico: uma sugestão para } \\
\text { iniciação ao violão }\end{array}$ & André Campos e Jodacil Damaceno \\
\hline
\end{tabular}

Além da menção aos métodos analisados na pesquisa, como $\mathbf{O}$ equilibrista das seis cordas, de Mariani (2002), e a Ciranda das seis cordas, de Pinto (2007), outros materiais foram indicados pelos professores entrevistados. Os Métodos de violão, editados pela Hal Leonard; First book for the guitar, de Noad (2009); e os métodos de violão elaborados por Rocha Filho (1966), Minhas Primeiras Notas ao Violão, volumes I e II - Coleção Mascarenhas; Pinto (2007), Iniciação ao violão, volumes I e II - Curso Progressivo de Violão; e Suzuki (1991), Guitar School, volumes I a IX, todos podem ser considerados. 


\subsection{PREPARAÇÃO DO PROFESSOR DE VIOLÃO}

Sob a perspectiva dos professores colaboradores da pesquisa, os conteúdos de ensino de violão direcionados para alunos de graduação que atuarão com o público infantil devem dar ênfase, sobretudo, às questões técnicas do instrumento, aos aspectos fisiológicos e psicológicos, e às estratégias de estudo, como concentração, atenção, foco, repetição e memória.

Todos os professores, de alguma maneira, concordam entre si sobre a importância de trabalhar-se com os estudantes da graduação as metodologias de ensino pensadas para o público infantil. Os professores Marcelo e Sarah relataram que, dentro de seu curso de licenciatura, eles possuem disciplinas específicas para a metodologia do instrumento, incluindo a faixa etária alvo da pesquisa, ou seja, crianças de cinco a doze anos de idade.

Sim, extremamente importante, no Curso de Graduação em Música da Universidade temos uma disciplina voltada para a metodologia do instrumento: "Metodologia do Ensino e Aprendizagem do Instrumento 1 e 2". Na Metodologia, 1 o foco é a iniciação ao violão. (Questionário - professora Sarah, 2016).

Eu tenho pouca experiência para falar sobre isso na graduação. Creio que para este tipo de discussão o profissional tem que ter tido experiência e leitura prática no ensino de instrumento para este público. [...] Em uma Licenciatura em Violão, com certeza, seria extremamente relevante e caberia o desenvolvimento de um programa para isto. $\mathrm{Na}$ minha experiência em graduação, com algumas exceções, o tempo é curto para tudo. Prefiro focar e proporcionar um domínio instrumental decente, com estímulos didáticos, do que fazer quase nada de muita coisa. (Questionário - professor Fabio, 2016).

Acho importantíssimo. No curso de Música da universidade [...] temos a disciplina Metodologia do Ensino e Aprendizado do Instrumento $1 \mathrm{e}$ 2, que aborda questões relativas à iniciação ao violão, incluindo aí esta faixa etária. (Questionário - professor Marcelo, 2016).

O professor Fabio, mesmo considerando importante trabalharem-se os aspectos pedagógicos em um curso de graduação, considera que

[...] em uma Licenciatura em Música pode ser importante, mas não mais importante do que o domínio técnico do instrumento ou questões didáticas gerais do instrumento e o uso como instrumento de apoio 
para processos de musicalização em ambiente escolar. (Questionário professor Fabio, 2016).

Este professor parte do argumento de que o educador musical deverá concentrarse no desenvolvimento técnico do instrumento, deixando, nesse caso, a parte pedagógica como sendo um fator secundário. Para ele, é fundamental que o educador seja capaz de desenvolver formas de como passar o conteúdo para o estudante a fim de que este compreenda e, desse modo, facilite-se o seu aprendizado. Sob a perspectiva desse professor, sem o domínio técnico, não se teriam condições de ensinar o instrumento, de " [...] ter uma experiência instrumental significativa para que o violão seja de fato um instrumento de apoio para o educador musical e não algo com o que o professor não tenha nenhuma desenvoltura" (Questionário - professor Fabio, 2016). Diferentemente, Matheus relata que

Os alunos serão preparados para atuarem com música em escolas [...], deste modo, o uso do violão é apenas como ferramenta para os futuros professores, que não necessariamente irão ensinar violão, mas sim aulas de música. (Questionário - professor Matheus, 2016).

Para este professor, não basta o educador musical compreender apenas sobre a técnica instrumental, é importante entender como passar esse conhecimento para o estudante a fim de que haja compreensão do conteúdo. Deste modo, deve-se levar o estudante de graduação a desenvolver um trabalho musical com seus alunos para além dos aspectos técnicos do instrumento.

Nos trabalhos de Santos (2013) e Oliveira (2013; 2014), direcionados para o ensino coletivo de violão, segue-se a mesma linha de pensamento do professor Matheus, que se concentra em proporcionar experiências musicais significativas às crianças, trabalhando aspectos que vão além do desenvolvimento técnico musical, sendo, deste modo, "[...] o desenvolvimento técnico no instrumento [...] tratado como uma consequência das várias atividades que irão privilegiar o fazer musical em grupo" (SANTOS, 2013, p. 15). 
Em suas abordagens metodológicas, os professores relataram a importância de conhecerem-se os aspectos pedagógicos e técnicos do instrumento, trabalhando-se com a postura; colocação de mão direita e mão esquerda; análise dos métodos disponíveis para esse público; estratégias de estudos; leitura de estudos e obras musicais em vários níveis para o ensino do violão, englobando exercícios e repertórios. Mencionaram ainda a importância de trabalharem com esses conteúdos relacionando-os aos aspectos fisiológicos e psicológicos da criança

São abordados com um olhar pelo prisma da pedagogia do instrumento, há que se observar o quanto abordam a questão musical em detrimento da tecnicista. (Questionário - professor Dante, 2016).

Os conteúdos abordados são relacionados a: aspectos fisiológicos e psicológicos: sistema nervoso e emoção; estratégias de estudo, como concentração, atenção, foco, repetição e memória; análise dos métodos para violão, para conhecerem o que já foi escrito para o ensino do violão; abordagem específica sobre a iniciação ao violão; leitura de estudos e obras musicais em vários níveis para o ensino do violão, englobando exercícios e repertório. (Questionário - professora Sarah, 2016).

Normalmente, não concordo com o uso de métodos de ensino de violão, pois todo os que eu conheço são de duas categorias: repertório europeu tradicional ou dicionários de acordes para música popular. Também não concordo com o caráter progressivo da maior parte dos métodos, por eles não terem um apelo muito grande para o público que trabalho. Mas talvez eu tenha de refletir e descobrir como posso abordá-los de uma forma útil na graduação. (Questionário - professor Fabio, 2016).

Nas aulas de violão, este conteúdo é abordado tangencialmente em momentos de discussões relativas à formação do licenciando, sua obrigatoriedade de conhecer tanto a técnica e repertório do instrumento como os métodos, coleções álbuns e repertórios para iniciantes. As metodologias para a iniciação ao instrumento são vistas na disciplina Metodologia do Ensino e Aprendizado do Instrumento 1 e 2 [...] (Questionário - professor Marcelo, 2016).

Refletir a respeito da importância da escolha de repertório na contemporaneidade e sobre os valores que cada música carrega parece ser a ênfase dada por Fabio, que se mantém notadamente contrário ao trabalho que enfatiza as obras musicais do repertório clássico e de música popular cifrada. Conforme aponta Fonterrada (1997), olhar para um repertório mais contemporâneo poderia ajudar a 
elucidar a necessidade de ampliação do universo cultural e musical do aluno. Sob esta perspectiva, seria preciso desenvolver o conhecimento de repertório musical escolhido para servir de sustentação à cultura musical dos alunos do curso, professores ou dos futuros professores de música.

Outra alternativa seria explorar aspectos de composição, apreciação e performance, relacionando-se estes pontos ao uso da literatura e aos aspectos técnicos do instrumento, como mencionam os trabalhos de Santos (2013), Oliveira (2013), Fidalgo, Macêdo e Tourinho (2014), e de Comini, Barreto e Victor (2016), que direcionam o ensino musical do instrumento violão para crianças através do sistema C(L)A(S)P, amplamente difundido em Swanwick (2003)².

Esta mesma proposta é, de certo modo, abordada pelo professor Matheus, que propõe a elaboração de trabalhos executando, ouvindo e analisando obras existentes e criando outras em que várias técnicas de criação individual e coletiva sejam exploradas.

Nunes e Faria (2011) ajudam a compreender a importância de o professor conhecer a fundo a matéria que vai ensinar, pois isso é “[...] indispensável para comunicar aos alunos a motivação que se costuma considerar mais valiosa" (NUNES; FARIA, 2011, p. 9). Assim, é fundamental ao professor (que ensina violão para os futuros professores que atuarão com diversos públicos e faixas-etárias) transmitir também o interesse sobre o conteúdo que está sento ministrado, manifestando igualmente domínio técnico e prazer em passar esses conteúdos.

\section{CONSIDERAÇÕES FINAIS}

A temática desta pesquisa surgiu das dificuldades em planejar e desenvolver estratégias de ensino de violão para crianças na faixa etária de cinco a doze anos.

\footnotetext{
${ }^{2}$ Este autor utiliza o modelo $\mathrm{C}(\mathrm{L}) \mathrm{A}(\mathrm{S}) \mathrm{P}$, que é uma visão filosófica e não um método de educação musical. Nesta proposta, há uma ênfase no envolvimento direto dos alunos com a música através da composição, da apreciação e da execução. O autor atribui aos estudos de literatura e técnica um papel complementar, ainda que os admitindo como sendo necessários no ensino. Além de tocar o repertório, fazer exercícios técnicos, apreciar música, inventar e improvisar, os alunos recebem também informações para contextualizar o seu aprendizado, nunca esquecendo que o fazer direito é o objetivo final (FRANÇA; SWANWICK, 2002).
} 
O contato com profissionais que atuam como professores em cursos de formação inicial partiu da necessidade de conhecer outras práticas de ensino do instrumento violão sob a perspectiva de quem forma o futuro professor.

Buscou-se encontrar soluções pedagógicas para tornar as aulas mais prazerosas e significativas; modelos de condução dos estudantes para o desenvolvimento musical; indicações de como alcançar o domínio das técnicas do instrumento violão; e, principalmente, formas de despertar o interesse pelas aulas de música.

Conhecendo-se novas estratégias, métodos utilizados e concepções de ensino, entende-se que é possível ampliar também os conhecimentos que se têm sobre o ensino de violão para crianças.

Para ampliar o entendimento sobre o tema proposto aqui, foi necessário identificar os materiais pedagógicos que estavam disponíveis no mercado brasileiro e analisar as propostas metodológicas de ensino de violão para crianças com foco na faixa etária de cinco a doze anos de idade. A partir deste levantamento prévio, foi possível perceber que são poucos os materiais disponíveis no mercado voltados especificamente para crianças e que, em sua maioria, os métodos se concentram na iniciação do instrumento do violão, não especificando a faixa etária ou, então, quando a especificam, referem-se ao ensino de outros instrumentos.

Foi possível perceber que a aula de instrumento para a criança não precisa naturalmente estar focada apenas nos aspetos técnicos do instrumento. Neste sentido, as atividades musicais explorando a improvisação, composição, apreciação e performance são totalmente válidas para serem aplicadas em uma aula de violão. Para isso, é importante que o educador conheça as características de aprendizagem da criança e proponha aulas com enfoque lúdico quando atuar com a infância.

Os trabalhos analisados com foco no ensino de violão voltado à faixa etária de cinco a doze anos tendem a desenvolver suas aulas a partir do coletivo. Desta maneira, os alunos são levados a criar maiores relações com o próximo e com a música, despertando um maior interesse musical. 
Outro ponto importante na abordagem do ensino musical para crianças é a relação de afetividade ou empatia a ser construída entre professor e aluno. Os autores e os colaboradores da pesquisa ajudaram a esclarecer que é fundamental que o educador mantenha uma relação de afetividade com o aluno, demonstrando interesse, conhecendo as preferências musicais, o contexto social, o processo cognitivo e os estágios de aprendizagem de cada um. A ausência de envolvimento emocional satisfatório pode levar o trabalho pedagógico a tornar-se difícil e infrutífero. Por outro lado, através do afeto e da empatia, o professor contribui para o desenvolvimento cognitivo da criança, pois, assim, o aluno passa a sentir-se valorizado, o que contribui para a motivação do estudante no desejo de apreender.

Através da realização do questionário autoadministrado, um dos professores participantes demonstrou que considera mais importante que o aluno de licenciatura foque seus estudos sobre a parte técnica do instrumento em detrimento da questão pedagógica. Diferentemente dele, todos os demais ressaltaram que é preciso dar maior ênfase aos aspectos metodológicos a fim de que o educador musical seja capaz de transportar o conhecimento musical, estimulando a criança a desenvolver-se musicalmente. Desta forma, o profissional que atuará com crianças precisa, necessariamente, ter um apoio pedagógico e não somente conhecer a parte técnica.

A técnica do instrumento e a pedagogia devem caminhar lado a lado para quem pretende atuar na área de ensino. Contudo, os professores participantes desta pesquisa pareceram buscar "culpados" para os problemas vivenciados em suas aulas (família, atividades extras das crianças, interesses etc.). Neste ponto, questiona-se: mas e a reflexão sobre as próprias práticas? Por que as crianças são sempre as responsáveis pelas dificuldades? Os profissionais buscam alguma "criança ideal"? Que criança eles esperam encontrar nas aulas? Como planejar para as crianças que se tem e não para aquelas que se idealiza? E a própria formação enquanto professores de violão precisa ou não ser revista?

Novamente, evidencia-se a função do violão na formação do educador: formar o futuro professor de violão ou formar o professor de música que usa o violão para se expressar musicalmente, acompanhar canções etc.? 
Deve-se, do mesmo modo, refletir sobre como os futuros professores que, certamente, em algum momento, poderão atuar com essa faixa etária, estão sendo preparados para isso. Quais materiais e conteúdo são direcionados aos estudantes para atuar nessa área?

Como futuros professores de música esses profissionais deverão estar aptos a desenvolver um trabalho pedagógico com eficácia. Para isso, é fundamental compreender as características de cada público e os caminhos metodológicos que se devem seguir.

Com esta pesquisa, não se pretendeu esgotar o assunto. Acredita-se que novos trabalhos podem ser realizados, principalmente em relação à produção de novos materiais didáticos, novas estratégias pedagógicas, produção de arranjos e criação de repertórios para práticas coletivas de musicalização. Parecem ser estas as lacunas que a revisão de literatura evidencia.

A partir da elaboração do trabalho de conclusão do curso, revisando-se práticas pedagógicas e a preparação das aulas de violão para as crianças, pôde-se identificar a importância da reflexão e do aprofundamento na temática. Espera-se que este trabalho contribua para que as aulas de violão para crianças tenham, a partir de agora, outro viés, fruto do conhecimento expandido, proporcionado pelas análises do material ora apresentado.

\section{REFERÊNCIAS}

BRASIL. Conselho Nacional de Educação. Resolução No 2, de 8 de março de 2004. Disponível em: $<$ http://portal.mec.gov.br/cne/arquivos/pdf/CES02-04.pdf $>$. Acesso em:20 de abr. de 2017.

. Ministério da Educação. Portal MEC. Conselho Nacional de Educação - Conselho Pleno. Resolução CNE/CP n. 1, de 18 de fevereiro de 2002. Disponível em: http://portal.mec.gov.br/cne/arquivos/pdf/rcp01 02.pdf. Acesso em: 21 jun. 2017.

Parecer do CNE/CP 009/2001, que estabelece as Diretrizes Curriculares Nacionais para a Formação de Professores da Educação Básica, em nível superior, curso de licenciatura, de graduação plena. Disponível em: http://portal.mec.gov.br/cne/arquivos/pdf/009.pdf Acesso em: 20 de abr. de 2017. 


\section{EDUCACĀĀO,

Lei n. 8.069, de 13 de julho de 1990. Dispõe sobre o estatuto da criança e do adolescente e dá outras providências. Disponível em: $<$ https://www2.senado.leg.br/bdsf/bitstream/handle/id/70318/64.pdf?sequence=3>. Acesso em: 16 nov. 2016.

COMINI, Doalcei; BARRETO FILHO, Eduardo; VICTOR, Thiago. Sonhando em Cordas. In: XXVI Congresso da Associação Nacional de Pesquisa e Pós-Graduação em Música (ANPPOM). Anais... Belo Horizonte: UFMG, 2016. p.1-8. Disponível em: http:/www.anppom.com.br/congressos/index.php/26anppom/bh2016/paper/view/4095. Acesso em: 21 jun. 2017.

FIDALGO, Otavio Jorge; MACEDO, Mabel; TOURINHO, Cristina. Propostas e atividades para a iniciação musical e ensino coletivo de violão para crianças entre 7 e 11 anos. In: XXIV Congresso da Anppom. Anais... São Paulo, 2014. Disponível em: http://www.anppom.com.br/congressos/index.php/24anppom/SaoPaulo2014/paper/view/2988.

Acesso em: 19 out. 2016.

FIREMAN, Milson. A escolha de repertorio na aula de violão como uma proposta cognitiva. Em Pauta. Porto Alegre, v. 18, n. 30, janeiro a junho 2007. p. 93-128.

FONTERRADA, Marisa. A linha e a rede. In: Simpósio Paranaense de Educação Musical, $17^{\circ}$ Festival de Música. Anais... Londrina: UEL, 1997. p. 7-17.

FRANÇA, Cecília Cavalieri; SWANWICK, Keith. Composição, apreciação e performance na educação musical: teoria, pesquisa e prática. Em Pauta. Porto Alegre, v.13, n. 21, p. 5-41, 2002.

GODOY, Arilda S. Pesquisa Qualitativa: tipos fundamentais. In: Revista de Administração de Empresas (RAE). São Paulo, v. 35, n. 2, p. 57-63, 1995.

GRAY, David E. Pesquisa no mundo real. 2. ed. Porto Alegre: Penso, 2012.

MARIANI, Silvana. O equilibrista das seis cordas: método de violão para crianças. Curitiba: UFPR, 2002.

MOYSÉS, Gerson Luís Russo; MOORI Roberto Giro. Coleta de dados para a pesquisa acadêmica: um estudo sobre a elaboração, a validação e a aplicação eletrônica de questionário. In: XXVII Encontro Nacional de Engenharia de Produção. Foz do Iguaçu, 9 a 11 de outubro de $2007 . \quad$ Disponível em: <http://www.abepro.org.br/biblioteca/ENEGEP2007_TR660483_9457.pdf>. Acesso em: 27 abr. 2017.

NOAD, Frederick M. First book for the guitar. Ed. Hal Leonard, 2009,192 p

NUNES, Simone Aparecida de Aquino; FARIA, Moacir Alves de. Motivação do Aluno de 3 a 7 anos. In: Revista Eletrônica Saberes da Educação, v. 2, n. 1, 2011. p. 1-12. Disponível em: < http://docs.uninove.br/arte/fac/publicacoes/pdf/v2-n1-2011/Simone.pdf >. Acesso em: 11 ago. 2016.

OLIVEIRA, Rafael Dias de. Jogos e brincadeiras no ensino coletivo de violão para crianças. In: XVI Encontro Regional Sul da ABEM - Educação musical: formação humana, ética e produção 
de conhecimento. Anais... Blumenau: FURB, 2014. Disponível em: http://abemeducacaomusical.com.br/conferencias/index.php/regional_sul/regional_sul/paper/vie wFile/481/37. Acesso em: 22 jun. 2017.

Jogos e brincadeiras no ensino coletivo de violão para crianças. Monografia (Graduação - Licenciatura em Música) - Universidade do Estado de Santa Catarina, Centro de Artes, Florianópolis, 2013.

PINTO, Henrique. Ciranda das seis cordas: iniciação infantil ao violão. São Paulo: Ed. Ricordi, 2007.

. Iniciação ao violão, volumes I e II - Curso Progressivo de Violão. 1999.

REIS, Willian Mota Caitano dos. Metodologias de Ensino de Violão: a criança em foco. 2016. 52f. Trabalho de Conclusão de Curso (Licenciatura em Música) - Universidade do Estado de Santa Catarina. Departamento de Música/Centro de Artes, Florianópolis, 2016.

REIS, Willian Mota Caitano dos; SCHAMBECK Regina Finck. Ensino de Violão para Crianças: materiais pedagógicos em foco. VII Encontro de Pesquisa e Extensão do Grupo MusE, 2017, Florianópolis, Anais... Florianópolis: UDESC, CEART, 27 a de abril de 2017, p.54-65. Disponível em: http://grupodepesquisamuse.files.wordpress.com/2015/04/anais-do-vencontro-do-muse-v-3.pdf. Acesso em 31 maio 2017. ISSN: 2446-5143

ROCHA FILHO, Othon Gomes da. Minhas primeiras notas ao violão, Volumes I e II Irmãos Vitale Editores, 1966 - Coleção Mascarenhas

SANTOS, Gabriel Bertuol. Violão Coletivo: propostas para o ensino de violão. Monografia (Graduação - Licenciatura em Música) - Universidade do Estado de Santa Catarina, Centro de Artes, Florianópolis, 2013.

SILVA, Nelma Albino da. A importância da afetividade na relação professor-aluno. Brasil Escola. Monografia (Graduação em Pedagogia) - Faculdade de Educação, Universidade do Estado do Rio de Janeiro, Rio de Janeiro, 2013. 44 p. Disponível em: http://monografias.brasilescola.uol.com.br/pedagogia/a-importancia-afetividade-na-relacaoprofessor-aluno.htm. Acesso em: 21 jun. 2017.

SUZUKI, Shinichi. Guitar School, volumes I a IX, 1991.

SWANWICK, Keith. Ensinando música musicalmente. São Paulo: Editora Moderna, 2003. 